\title{
Growth and Nisin Production of a Strain of Streptococcus lactis
}

\author{
By A. HIRSCH \\ National Institute for Research in Dairying, University of Reading
}

SUMMARY : Stable mutant colonies were picked from a parent strain of Streptococcus lactis which gave improved yields of nisin; further improvement could not be produced by means of colchicine or camphor.

Nisin is stable in the culture fluid at acid $\mathrm{pH}$ values, but is inactivated by Seitz filtration or heating at $\mathrm{pH} 6$ to 9 . A 'nisinase' was not found.

In the presence of sufficient glucose, growth was increased when the lactic acid formed was neutralized, the concentration of pantothenic acid becoming the limiting factor. Maximum nisin yields were obtained when, during fermentation in the presence of sufficient glucose and pantothenate at $23-30^{\circ}$, the $\mathrm{pH}$ was stabilized at $c .6$, which is the $\mathrm{pH}$ optimum for nisin synthesis.

Sodium lactate and nisin are only slightly inhibitory to the organism. Growth comes to an end because of the maximum limiting population density (' $M$ '-concentration) of cells, and is not due to the exhaustion of food or accumulation of toxic products.

Mattick \& Hirsch (1944) described an antibiotic substance produced by group N streptococci; clinical applications of this antibiotic were described by Taylor, Hirsch \& Mattick (1949) and Hirsch \& Mattick (1949). Mattick \& Hirsch (1947) described a glucose yeast-extract medium for the production, on a large laboratory scale, of this antibiotic, now called nisin.

The yield of nisin with this culture medium was only c. 80 units $/ \mathrm{ml}$. (pure nisin contains $c .50$ units $/ \mu \mathrm{g}$.) and compared unfavourably with that of penicillin or streptomycin. The work now described was designed to increase the yield of nisin and a meat-extract peptone medium replaced the yeast-extract medium.

\section{MATERIALS AND METHODS}

Media. For daily subculturing glucose Lemco broth (Mattick \& Hirsch, 1947) and for storage bullock's heart medium were used. Evans's peptone (Evans Medical Supplies Ltd., Speke, Liverpool) was used throughout. For growth experiments the following medium was used: peptone $1 \%$, Lab-lemco $1 \%$, glucose up to $2 \cdot 5 \%$. To the basal medium various additions were made as described below. The vitamin requirements were tested in an acid-hydrolyzed casein medium (Niven, 1944).

The cultures were, unless otherwise stated, incubated at $30^{\circ} \pm 0 \cdot 1^{\circ}$ in conical flasks of $750 \mathrm{ml}$. capacity and containing $300 \mathrm{ml}$. of medium inoculated with a $3 \%(\mathrm{v} / \mathrm{v})$ inoculum. Values of $\mathrm{pH}$ were obtained by means of a glass electrode; optical densities were read in $1 \mathrm{~cm}$. cells with a 'Biochem' absorptiometer (Adam Hilger Ltd., London) using the orange filter. Assays were made by the lag-phase method (Hirsch, 1950).

For work with synthetic resins a $1.5 \mathrm{l}$. conical flask with an outlet at the 


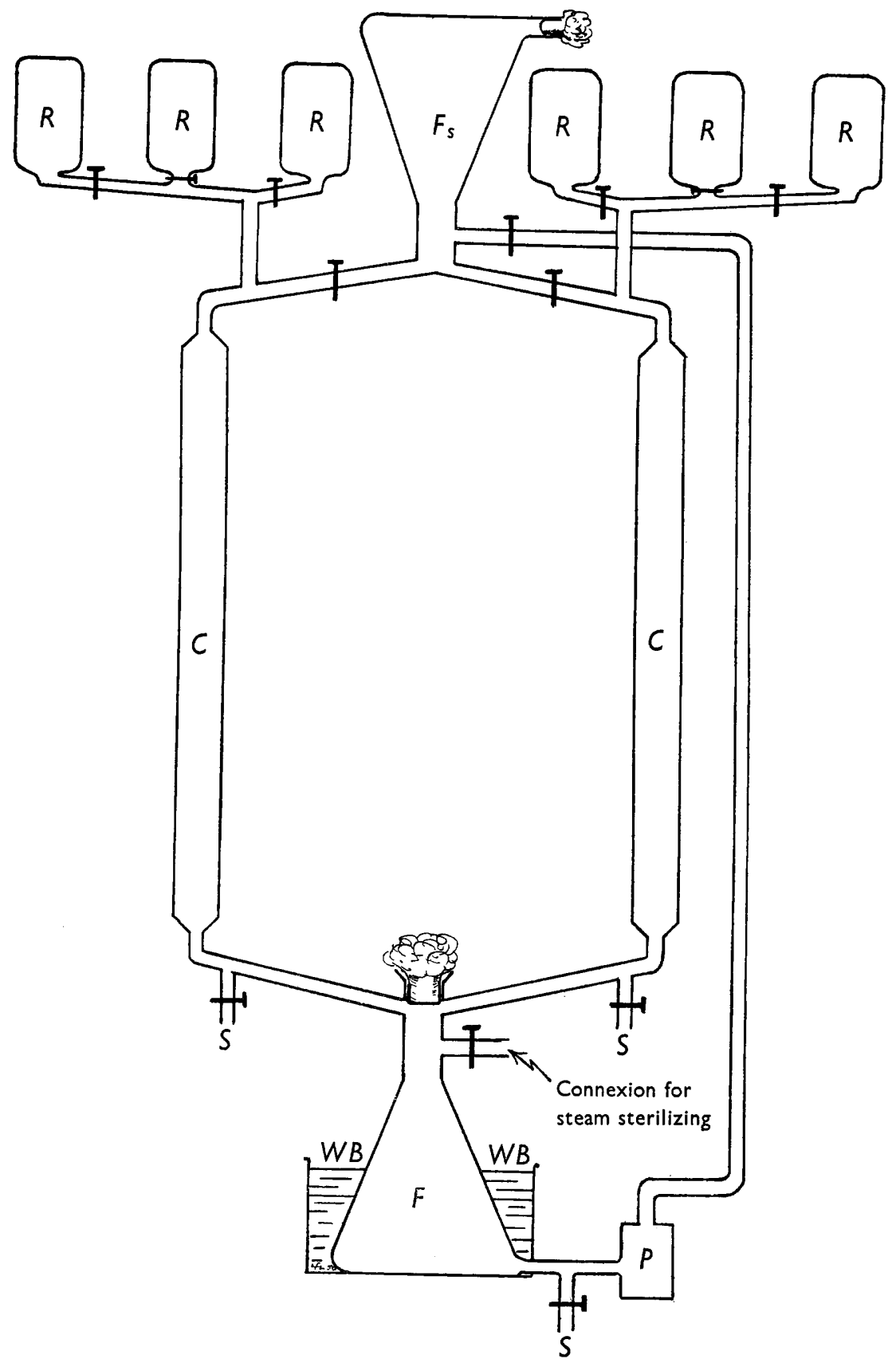

Fig. 1. Apparatus for the removal of nisin and lactic acid by means of synthetic resins from growing cultures of Strep. lactis 354/07. $F=$ fermentation vessel; $F_{s}=$ fermentation vessel storage; $P=$ pump; $W B=$ water-bath; $S=$ sampling points; $C=$ columns for synthetic resins; $R=$ reagents storage for columns. 
bottom was used to hold the culture. The culture could be pumped aseptically into a storage vessel and then gravity-fed over columns and returned to the conical flask. The columns could be regenerated or eluted with sterile solvents kept in storage vessels and fed by gravity over the columns (see Fig. 1). De-acidite $\boldsymbol{E}$ (Permutit Co. Ltd., London) was washed before use in 50 times its own wet-volume of distilled water, transferred to a column and 1.5 times its volume of $4 \%(\mathrm{w} / \mathrm{v}) \mathrm{Na}_{2} \mathrm{CO}_{3}$ run over it. It was then washed until the $\mathrm{pH}$ of the distilled water was $c .10 \cdot 5$. After use the column was regenerated with further additions of $4 \% \mathrm{Na}_{2} \mathrm{CO}_{3}$. Amberlite IRC-50 (Analytical Grade, British Drug Houses Ltd., London) was washed with 5 times its own wetvolume of distilled water, columns were made, then treated with two volumes of $0.1 \mathrm{~N}-\mathrm{NaOH}$ and washed with acetic acid-acetate $(0 \cdot 1 \mathrm{~m})$ buffer at $\mathrm{pH} 5.0$ until no change in the $\mathrm{pH}$ of the emerging buffer could be detected.

\section{RESULTS}

\section{Properties of the nisin-producing organism}

Strain selection. In 1944, strain 354 produced more nisin in milk (which it clotted readily) than in broth; with continued subcultivation in broth this strain lost its ability to clot milk and produced more nisin in broth than in milk. This 'broth trained' strain could not again be made to clot milk or to produce nisin in it. The cultures kept in broth began simultaneously to decline in their ability to produce nisin and the usual concentrations of about 80 units $/ \mathrm{ml}$. fell to 20 units $/ \mathrm{ml}$. The original milk-cultures were then streaked on Yeastrel glucose agar and single colonies picked. Of twenty-four new strains isolated twenty-one still produced more nisin in milk than in broth, two produced equal amounts in the two media and only one produced more nisin in broth than in milk (354/07). About 2 months after its isolation strain 354/07 was plated and single colonies picked; forty cultures tested were without exception good nisin producers, equalling but not surpassing strain 354/07. This latter strain has now been in use for 6 years without significant change; the work described below was carried out with this strain, which was also used by Berridge (1949).

From the parent strain, different isolates gave different yields of nisin but the high-yielding nisin strain (354/07) selected from it did not. It is not known whether all the strains of 354/07 in use to-day are still homogeneous. Other uncertainties were encountered. One was observed in experiments to find the optimum number of subcultures required to secure maximum nisin production after storage of the producer strain. Usually three to five subcultures were required; sometimes the strains showed a decline after the 8 th subculture. At other times one or two subcultures were sufficient and the strain still produced maximal nisin amounts after the 29th subculture.

Attempt to produce variants by treatment with colchicine and camphor. Neither colchicine, camphor or isopropylphenylcarbamate induced any changes in growth or nisin production of Strep. lactis.

Morphological changes during growth. Polypeptide capsules are known to 
occur in other species (Bovarnick, 1942). For a while, stained preparations of capsules could be obtained easily with strain 354/07; the strongly Gram-positive cocci were usually enclosed in pairs in a single capsule during the early part of the growth, 'zooglea' becoming more frequent as the culture reached an age of 10-15 hr. Later in this work cultures which showed no capsules were encountered. Examined by phase-contrast microscopy these cultures were observed to multiply; capsules could not be seen, nor could they be stained, but normal amounts of nisin were produced. It may be concluded that the likelihood of nisin being capsular material is small. Some observations of stained preparations (see, for instance, Fig. 2) indicated a change in the capsule (when this was present) corresponding to the appearance of nisin in broth.

\section{Some properties of nisin in culture fluids}

The initial $\mathrm{pH}$ value of the medium, $c . \mathrm{pH} \mathrm{7 \cdot 0}$, decreased to $c .4 \cdot 6$ after $24 \mathrm{hr}$. growth, the nisin being about equally distributed between the cells and the fluid. Nisin activity was lost during various treatments of the culture fluids. The effect of heating at various $\mathrm{pH}$ values is recorded in Table 1 , and the further effects of heating and filtration through Seitz-type filter-pads are recorded in Table 2 . With heat treatments the results were not clear-cut.

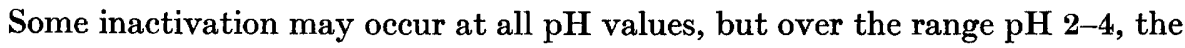
rate of liberation of nisin from the cells may equal that of its destruction. There appears to be greater stability at $\mathrm{pH} 7$ than at $\mathrm{pH} 6$. In the culture at the natural final $\mathrm{pH}$, the nisin activity remained unchanged for 10 days at room temperature.

Table 1. The stability of nisin in culture fluid at various $p H$ values (Culture fluid was centrifuged, adjusted to various pH values and boiled for 30 sec.)

$\begin{array}{lcc} & \text { Nisin in culture } \\ \text { fluid (\% of initial } & \text { Activity lost } \\ \text { pH } & \text { value) } & (\%) \\ 2 \cdot 0 & 100 & 0 \\ \mathbf{3 \cdot 0} & 78 & 0 \\ 4 \cdot 0 & 55 & 0 \\ 4 \cdot 65 * & 50 & 0 \\ \mathbf{5 \cdot 0} & 30 & 0 \\ \mathbf{6 \cdot 0} & c .20 & 30 \\ \mathbf{7 \cdot 0} & c .20 & 10(?) \\ 8 \cdot 0 & 17-20 & 50 \\ 9 \cdot 5 & 1-10 & 90\end{array}$

* $\mathrm{pH}$ value at end of ordinary fermentation in this medium.

It was of interest to see whether the stability of nisin was also reflected in the absence of a 'nisinase'. A strain of Bacillus subtilis used for penicillinase production was strongly inhibited. Species known to be insensitive to nisin, i.e. Bacterium coli and Strep. faecalis, similarly fail to produce a nisinase. From a sample of dried dung a mould of the genus Mucor was isolated which grew on $2 \%$ agar containing $0.5 \%$ crystalline nisin. The activity of the nisin 
Table 2. The inactivation of nisin in cultures subjected to various treatments at different $\mathrm{pH}$ values

\begin{tabular}{|c|c|c|c|c|c|c|c|}
\hline \multirow[b]{3}{*}{ pH } & \multicolumn{7}{|c|}{ Treatments } \\
\hline & \multirow[b]{2}{*}{ Seitz filtration } & \multicolumn{4}{|c|}{ Boiled for } & \multicolumn{2}{|c|}{$\begin{array}{l}\text { Boiled for } 10 \text { sec. then stored } \\
24 \mathrm{hr} \text {. at }\end{array}$} \\
\hline & & \multicolumn{5}{|c|}{ Activity lost (\%) } & $37^{\circ}$ \\
\hline 2 & 0 & 0 & 0 & 0 & c. 25 & - & - \\
\hline 3 & 27 & - & - & 0 & - & - & - \\
\hline 4 & 49 & - & 一 & 53 & - & - & - \\
\hline 5 & 100 & - & - & 62 & - & - & - \\
\hline 6 & 100 & - & - & c. 80 & - & c. 50 & c. 85 \\
\hline 7 & 100 & - & - & c. 80 & - & $c .85$ & c. 85 \\
\hline 8 & 100 & - & - & 100 & 一 & c. $85-100$ & c. $85-100$ \\
\hline 9 & - & - & - & 100 & - & c. 100 & c. 100 \\
\hline
\end{tabular}

was diminished by the growth of the mould, but when as little as $0 \cdot 1 \%$ peptone was incorporated in the medium the mould preferentially used the peptone, the activity of the nisin incorporated into the medium remaining unchanged.

The effect of the composition of the medium and cultural conditions on nisin production

Growth in glucose Lemco peptone broth. Plate-counts, optical density, pH, surface tension, nisin assay and staining reaction were followed continuously in a number of experiments. These observations are recorded in Fig. 2. With increasing numbers of cells there was a corresponding increase in optical density, but the correlation broke down after 8-10 hr. growth; this change appeared to be due not so much to differences between total and viable counts as to the changing morphology of the organism. Considerable metabolic activity preceded the appearance of nisin; the $\mathrm{pH}$ fell and the average surface tension decreased from 58 to 54 dynes $/ \mathrm{cm}$. In this medium the fermentation was complete in about $8 \mathrm{hr}$., at which time $c .0 .7 \%$ glucose out of the initial $1 \%$ had been utilized.

Effect of neutralization of lactic acid formed during fermentation. Rogers \& Whittier (1928) and Bernheimer \& Pappenheimer (1942) and others have shown that considerably increased growth was obtained when $\mathrm{NaOH}$ was periodically added to growing cultures of streptococci to neutralize the acid formed. Similar results were obtained in the present work (see Fig. 3 and 4). Even with the rich glucose peptone Lemco medium, increased amounts of growth (by optical density) were obtained by various additions to the broth, provided that periodic neutralization of acid formed was carried out and that sufficient glucose was present not to become a limiting factor. Liver extract gave the greatest optical density. The nisin production (Fig. 4) was also increased by neutralization, but $\mathrm{Ca}$ pantothenate alone was more effective in increasing the yield of nisin than either a mixture of all the known B-vitamins or liver extract. 
Microbiological assays on periodically neutralized broth which had initially contained $\mathbf{2 . 5} \%$ glucose showed that all the pantothenate had been used up.

The effect of buffers. Working with broths at controlled $\mathrm{pH}(5-6)$ various buffers were found further to promote the yield of nisin. Citrate and acetate appear to be the most effective single buffers; no specific effect due to acetate

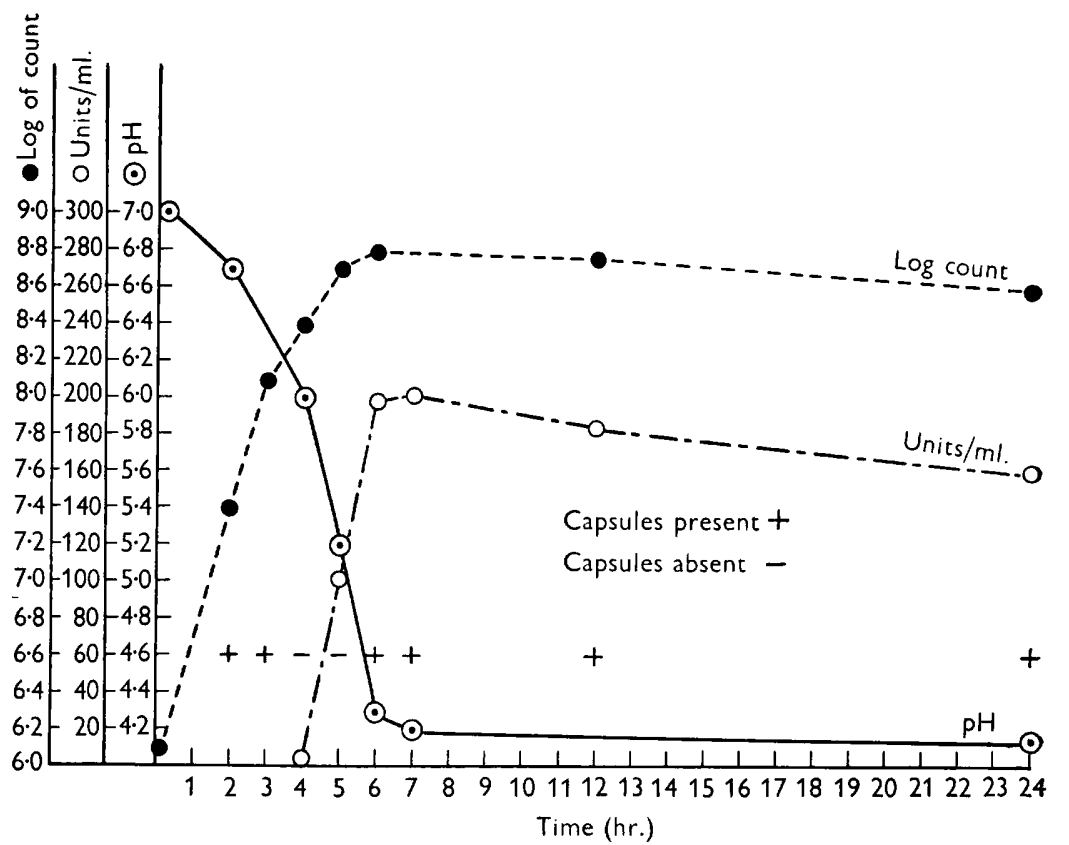

Fig. 2. The growth and nisin production of strain $354 / 07$ in glucose Lemco peptone broth.

only, as was suggested by the work of Guirard, Snell \& Williams (1946), was found in this medium. A summary of these findings is given in Table 3. A combination of all the buffers appears to be better than any single buffer. The differences between the average activities of the three groups were found to be significant by the $t$ test $(P=0 \cdot 01)$.

It was possible that the increased nisin production was due directly to the accumulation of salts, or that these exercised an indirect effect because of increased osmotic pressure. Experiment showed that increased $\mathrm{NaCl}$ or $\mathrm{Na}_{2} \mathrm{NO}_{3}$ concentrations diminished rather than improved growth and yields of nisin (cf. bottle 4 and 5 with bottle 3 , Table 4 ). It may be that nisin results from a synthesis (see below) and that the three-buffer combination was more effective in maintaining the medium near the optimum $\mathrm{pH}$ for nisin production than one or two of the buffers only. Titration curves prepared from media (see Table 3 ; medium no. 21 and 22 (high activity); 14, 17, 18 and 23 (medium activity); and 15 (low activity)) showed that high buffering power occurred at $\mathrm{pH} 5 \cdot 9-6 \cdot 1$ when nisin production also was high. In particular, medium no. 22 showed a marked peak in this $\mathrm{pH}$ range. 


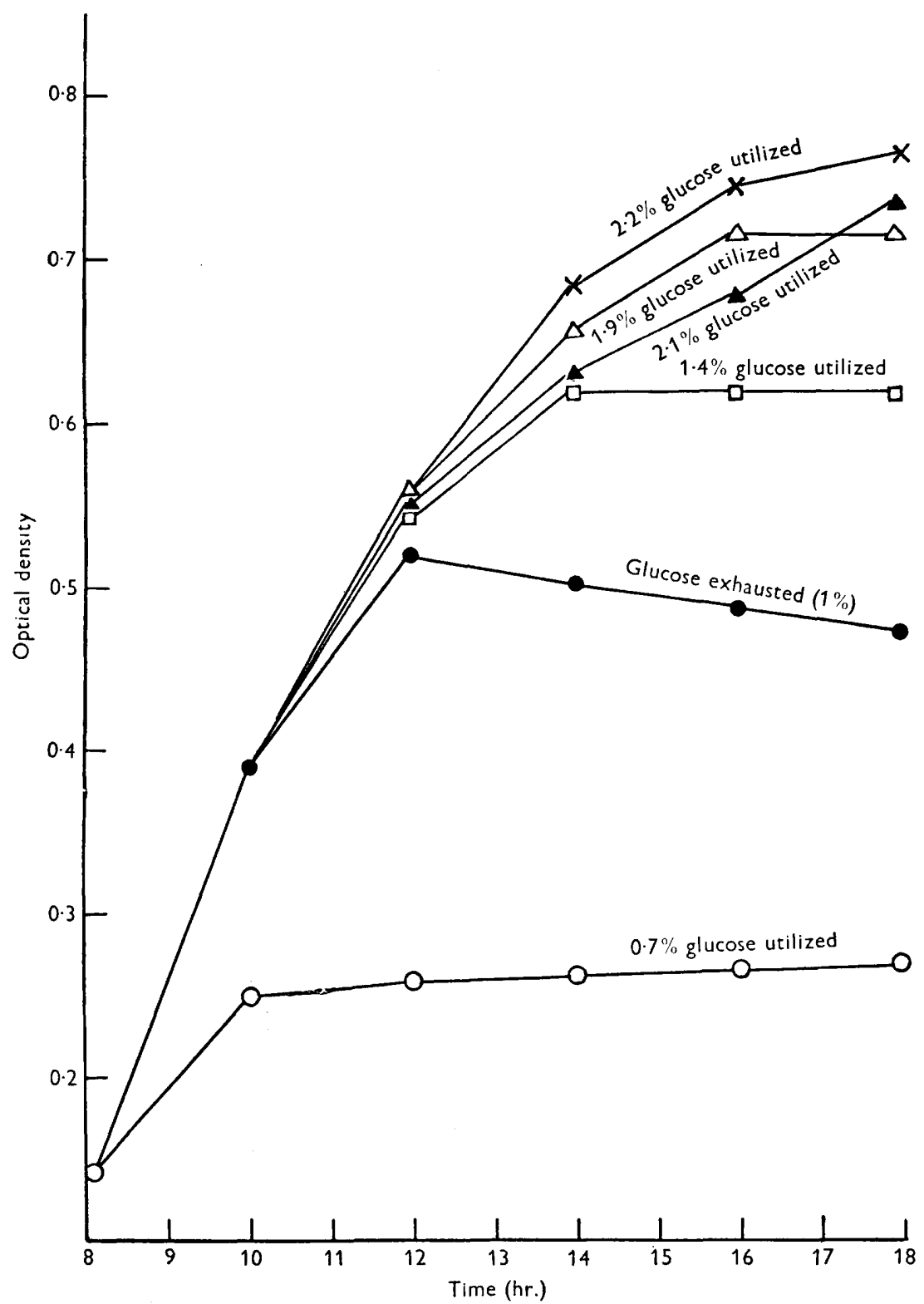

Fig. 3. The effect of certain additions on the growth of Strep. lactis as measured by optical density. $O=$ medium, normal fermentation; $O=$ medium, neutralized periodically; $\square=$ glucose initially to $2 \cdot 5 \%$, neutralized periodically; $\triangle=$ glucose initially to $2.5 \%$ +Ca pantothenate $(0 \cdot 6 \mu \mathrm{g} . / \mathrm{ml}$.), neutralized periodically; $\Delta=$ glucose initially to $2.5 \%$ +riboflavin $1 \mu \mathrm{g} . / \mathrm{ml}$., Ca pantothenate $1 \mu \mathrm{g} . / \mathrm{ml}$., nicotinic acid $1 \mu \mathrm{g} . / \mathrm{ml}$., pyridoxin $1 \mu \mathrm{g} . / \mathrm{ml}$., aneurin $0.1 \mu \mathrm{g} . / \mathrm{ml}$., biotin $0.001 \mu \mathrm{g} . / \mathrm{ml}$., xanthine $5 \mu \mathrm{g} . / \mathrm{ml}$., adenine $5 \mu \mathrm{g} . / \mathrm{ml}$, guanine $5 \mu \mathrm{g} . / \mathrm{ml}$, uracil $5 \mu \mathrm{g} . / \mathrm{ml}$, neutralized periodically; $x=$ glucose initially to $\mathbf{2 . 5} \%$ + liver extract, neutralized periodically. 


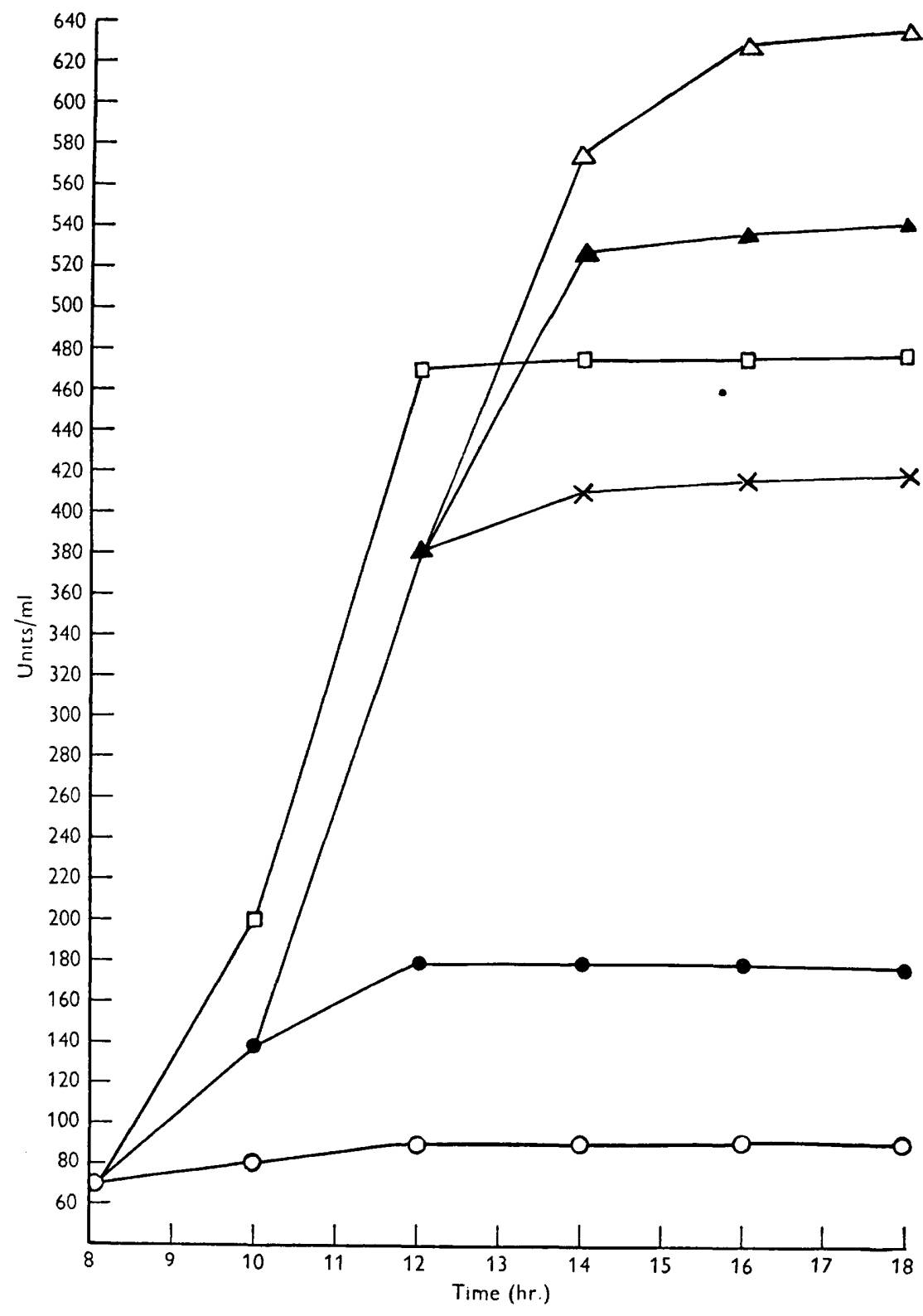

Fig. 4. The effect of certain additions on nisin production by Strep. lactis. $O=$ medium, normal fermentation; $\boldsymbol{O}=$ medium, heutralized periodically; $\square=$ glucose initially to $2.5 \%$, neutralized periodically; $\triangle=$ glucose initially to $2.5 \%+\mathrm{Ca}$ pantothenate $(0 \cdot 6 \mu \mathrm{g} . / \mathrm{ml}$.$) , neutralized periodically; \Delta=$ glucose initially to $2.5 \%+$ riboflavin $1 \mu \mathrm{g} . / \mathrm{ml}$., Ca pantothenate $1 \mu \mathrm{g} . / \mathrm{ml}$., nicotinic acid $1 \mu \mathrm{g} . / \mathrm{ml}$., pyridoxin $1 \mu \mathrm{g} . / \mathrm{ml}$, , aneurin $0 \cdot 1 \mu \mathrm{g} . / \mathrm{ml}$., biotin $0.001 \mu \mathrm{g} . / \mathrm{ml}$., xanthine $5 \mu \mathrm{g} . / \mathrm{ml}$, , adenine $5 \mu \mathrm{g} . / \mathrm{ml}$., guanine $5 \mu \mathrm{g} . / \mathrm{ml}$., uracil $5 \mu \mathrm{g} . / \mathrm{ml}$., neutralized periodically; $x=$ glucose initially to $2.5 \%+$ liver extract, neutralized periodically. 
Table 3. The effect on nisin formation of the addition of various buffer salts singly and in combinations to media maintained at $\mathrm{pH}$ 5-6 during growth

\begin{tabular}{|c|c|c|c|c|}
\hline \multirow{3}{*}{ Exp. no. } & \multicolumn{3}{|c|}{ (Ca pantothenate and glucose present in excess.) } & \multirow{3}{*}{$\begin{array}{l}\text { Yield of nisi } \\
\text { (units/ml.) }\end{array}$} \\
\hline & Acetate (\%) & Citrate (\%) & Phosphate (\%) & \\
\hline & \multicolumn{3}{|c|}{ Single buffers } & \\
\hline 1 & 0.5 & - & - & 319 \\
\hline $\mathbf{2}$ & 1 & - & - & 401 \\
\hline 3 & 1.5 & - & - & 664 \\
\hline 4 & $\mathbf{2}$ & - & - & 615 \\
\hline 5 & - & - & 0.5 & 210 \\
\hline 6 & - & - & 1 & 266 \\
\hline 7 & - & 0.5 & - & 276 \\
\hline 8 & - & 1 & - & 527 \\
\hline 9 & - & 1.5 & - & 771 \\
\hline \multirow[t]{2}{*}{10} & - & 2 & - & 720 \\
\hline & & & Average yield: & 477 \\
\hline \multicolumn{5}{|c|}{ Combinations of two buffers } \\
\hline 11 & 1 & - & 0.5 & 601 \\
\hline 12 & 1 & - & 1 & 897 \\
\hline 13 & 1.5 & - & 0.5 & 948 \\
\hline 14 & 1.5 & - & 1 & 1095 \\
\hline 15 & 1 & 0.5 & - & 379 \\
\hline 16 & 1 & 1 & - & 955 \\
\hline 17 & 1 & 1.5 & - & 1040 \\
\hline 18 & 1.5 & 1.5 & - & 1069 \\
\hline 19 & - & 1.5 & 0.5 & 815 \\
\hline \multirow[t]{2}{*}{20} & - & 1.5 & 1 & 783 \\
\hline & & & Average yield: & 858 \\
\hline \multicolumn{5}{|c|}{ Combinations of three buffers } \\
\hline 21 & 1 & 1 & 0.5 & 1950 \\
\hline 22 & 1.5 & I.5 & 0.5 & 1963 \\
\hline \multirow[t]{2}{*}{23} & 1 & 1 & 1 & 1255 \\
\hline & & & Average yield: & 1723 \\
\hline
\end{tabular}

Table 4 shows that bottle 6 containing only one buffer gave as good a nisin production as bottle 3 containing three buffers, probably because the former was maintained at $\mathrm{pH} 5 \cdot 9-6 \cdot 1$ by $\mathrm{NaOH}$ additions every $\frac{1}{4} \mathrm{hr}$. Further, bottle 6 gave much more nisin than bottle 1 (the composition of the medium in the two bottles was identical), bottle 1 was maintained at $\mathrm{pH} \mathrm{5-7}$ by addition of $\mathrm{NaOH}$ every $2 \mathrm{hr}$. The main effect of buffering thus appears to be due to the maintenance of the $\mathrm{pH}$ near the optimum. Table 4 also shows that there may be a specific stimulatory effect on nisin production, because more nisin was produced for the same optical density (bottle 8 ). Table 3 also shows that $2 \%$ of acetate, or citrate, was more than was required for an optimum effect. Similar result was also obtained with $1.5 \%$ phosphate.

The effect of other cultural conditions. The effect of temperature of incubation is shown in Table 5. Maximum growth and nisin production occurred at 25-30 ${ }^{\circ}$ At $37^{\circ}$ growth was more rapid but the final optical density reached was below that at $25-30^{\circ}$. When air was vigorously bubbled into a liquid culture 
Table 4. The effect of salt concentration and regularity of $\mathrm{pH}$ maintenance during growth on nisin production

(Strain 354/07 of Strep. lactis. Medium adjusted to pH 5-7 except Bottle no. 6 adjusted to $6 \cdot 0$.

\begin{tabular}{|c|c|c|c|c|}
\hline Bottle no. & Composition of medium & $\begin{array}{c}\mathrm{NaOH} \\
\text { additions each }\end{array}$ & $\begin{array}{c}\text { Final } \\
\text { optical } \\
\text { density }\end{array}$ & $\begin{array}{l}\text { Yield of nisin } \\
\text { (units/ml.) }\end{array}$ \\
\hline 1 & *Basal medium & 2 hr. & $1 \cdot 35$ & 615 \\
\hline $\mathbf{3}$ & $\begin{array}{l}\text { Basal medium }+1.5 \% \mathrm{Na} \text { citrate } \\
+0.5 \% \mathrm{~K}_{2} \mathrm{HPO}_{4}\end{array}$ & $2 \mathrm{hr}$. & 1.25 & 1660 \\
\hline 4 & $\begin{array}{l}\text { Basal medium }+1.5 \% \mathrm{Na} \text { citrate } \\
+0.5 \% \mathrm{~K}_{2} \mathrm{HPO}_{4}+1 \% \mathrm{NaCl}\end{array}$ & 2 hr. & $1 \cdot 05$ & 1020 \\
\hline 5 & $\begin{array}{l}\text { Basal medium }+1.5 \% \mathrm{Na} \text { citrate } \\
+0.5 \% \mathrm{~K}_{2} \mathrm{HPO}_{4}+1 \% \mathrm{NaNO}_{3}\end{array}$ & 2 hr. & $1 \cdot 15$ & 1070 \\
\hline 6 & Basal medium & $\frac{1}{4} \mathrm{hr}$. & $1 \cdot 35$ & 1680 \\
\hline 8 & $\begin{array}{l}\text { Basal medium }+1.5 \% \mathrm{Na} \text { citrate } \\
+0.5 \% \mathrm{~K}_{2} \mathrm{HPO}_{4}+1 \% \mathrm{Na}_{2} \mathrm{SO}_{4}\end{array}$ & $12 \mathrm{hr}$. & $1 \cdot 15$ & 2130 \\
\hline
\end{tabular}

For effect of salts compare bottle 3,4 and 5 .

For effect of pH compare bottle 1,3 and 6 .

For stimulation of nisin production compare bottles 3 and 8 .

* Basal medium was (in $\%, w / v)$ : Peptone (Evans) 1; Lab-Lemco 1; glucose 2.5; Na acetate 1.5 ; Ca pantothenate $0.6 \mu \mathrm{g} . / \mathrm{ml}$.

Table 5. The effect of temperature on growth of, and nisin production by Strep. lactis, strain 354/07

(pH maintained at 5-6 during growth. Ca pantothenate and glucose in excess.)

\begin{tabular}{|c|c|c|c|c|c|c|c|}
\hline & & & & nperat & & & \\
\hline & $18^{\circ}$ & $23 \cdot 6^{\circ}$ & $\mathbf{2 4} \cdot \mathbf{5}^{\circ}$ & $25 \cdot 9^{\circ}$ & $28.5^{\circ}$ & $30 \cdot 7^{\circ}$ & $37^{\circ}$ \\
\hline $\begin{array}{l}\text { Time taken to compl } \\
\text { fermentation (hr.): }\end{array}$ & 28 & 25 & 23 & 21 & 20 & 21 & 16 \\
\hline At the end of fermen & & & & & & & \\
\hline Optical density: & 0.96 & $1 \cdot 09$ & $1 \cdot 10$ & $1 \cdot 15$ & $1 \cdot 15$ & $1 \cdot 12$ & 0.91 \\
\hline Nisin, units/ml.: & 369 & 452 & 495 & 542 & 552 & 508 & 386 \\
\hline
\end{tabular}

the growth was delayed and with it the production of nisin, but the end-product appeared normal (cf. Rahn \& Richardson, 1942). Nisin production appeared to be normal under strictly anaerobic conditions.

\section{Factors affecting the end of metabolism}

After it was found that the pantothenic acid in the medium initially used was exhausted at the end of growth, an excess of $\mathrm{Ca}$ pantothenate was always included in the media $(0 \cdot 6 \mu \mathrm{g} . / \mathrm{ml}$. medium). It was possible that the other $B$ vitamins also became exhausted, since even in the rich medium used increased optical densities followed their addition; nisin production was, however, decreased (Fig. 3 and 4). Thus it seems unlikely that nisin production was limited by exhaustion of $B$ vitamins other than pantothenic acid. In agreement with Niven's (1944) findings the results showed that pantothenic acid, riboflavin, nicotinic acid and biotin were essential for growth and that pyridoxin was 
stimulatory. Growth and nisin production were parallel. It is also possible that a specific nitrogen source becomes exhausted, but this could not be demonstrated. When Lab-Lemco or peptone or both were added to media controlled at $\mathrm{pH} 6$ at the end of the fermentation, neither prolongation of growth nor increase in nisin production resulted.

Three further changes occurred in the medium as the growth proceeded. The surface tension fell from 58 to 54 dynes $/ \mathrm{cm}$. This is not of itself enough to stop growth, since according to Ayres, Rupp \& Johnson (1923), Strep. lactis could grow at a surface tension as low as 40 dynes $/ \mathrm{cm}$. Nevertheless, this was one of the unfavourable changes and possibly had an adverse effect.

Table 6. The effect of sodium lactate on growth of Strep. lactis, strain 354/07

\begin{tabular}{|c|c|c|c|}
\hline \multicolumn{2}{|c|}{ Na lactate added at start } & \multicolumn{2}{|c|}{$\begin{array}{l}\text { Na lactate added after } 6 \mathrm{hr} \text {. of } \\
\text { growth and cultures then } \\
\text { re-incubated for } 12 \mathrm{hr} \text {. }\end{array}$} \\
\hline Na lactate $(\%)$ & $\begin{array}{c}\text { Final optical } \\
\text { density }\end{array}$ & $\mathrm{Na}$ lactate $(\%)$ & $\begin{array}{c}\text { Final optical } \\
\text { density }\end{array}$ \\
\hline o & $0 \cdot 84$ & - & - \\
\hline 1 & 0.50 & $\mathbf{0}$ & $0 \cdot 84$ \\
\hline 2 & 0.41 & $1 \cdot 25$ & $0 \cdot 62$ \\
\hline 3 & $0 \cdot 17$ & $2 \cdot 5$ & 0.53 \\
\hline 4 & 0.09 & 5 & 0.30 \\
\hline $\mathbf{5}$ & $0 \cdot 04$ & $7 \cdot 5$ & $0 \cdot 34$ \\
\hline 6 & $0 \cdot 04$ & 10 & $0 \cdot 26$ \\
\hline
\end{tabular}

Rogers (1928) was probably the first to describe antibiotic phenomena among the lactic streptococci and concluded that the antibiotic inhibited the organism which produced it. This has to some extent been found in the present work. Using a serial dilution end-point technique about $1000 \mathrm{units} / \mathrm{ml}$. were found to inhibit the producer organism; some 3 years later this experiment was repeated and the self-inhibition titre had risen to about 2000 units $/ \mathrm{ml}$. There is little or no effect at 100-200 units/ml., the usual concentration of nisin produced in a culture.

Rogers also investigated the possible limiting effect of lactate (Rogers \& Whittier, 1928), but reached no definite conclusion. When lactate was added to growing cultures up to $0.06 \mathrm{M}(0.5 \%)$ no differences in the resulting count were detected. As shown earlier in the present work, up to $2 \cdot 3 \%$ of glucose may be used; this should yield $c .4 .5 \%$ lactic acid $(0.5 \mathrm{M})$ with this homofermentative strain. Even with this concentration of lactic acid (see Table 6) there was no clear-cut effect. When the lactate was added before growth began, as little as $1 \%$ was sufficient to diminish the amount of growth. At 4-6\% $\mathrm{Na}$ lactate growth was virtually stopped, in agreement with the glucose utilization figures above. When lactate was added after the growth had begun, even $10 \%$ of lactate did not completely stop growth, although there was a progressive decrease in the amount of growth with increasing concentrations of lactate, which is therefore much less toxic than might be supposed. 


\section{The removal of nisin and lactate from culture fluids}

Using the simple apparatus described earlier, growing cultures were pumped over columns of synthetic resin. The use of columns was essential with Deacidite $\mathbf{E}$, which was used for the removal of lactic acid. This resin was found to be unsuitable in a batch process, as apparently acidic substances other than lactic acid were adsorbed and growth was stopped. In a column, however, lactic acid was adsorbed sufficiently specifically or it displaced other components already adsorbed; no interference with growth was observed when a culturefluid volume of 40 to 3 volumes of resin was used. In a batch process Deacidite $\mathbf{E}$ also adsorbed nisin, which could be eluted with weak acids.

A number of synthetic resins was tested for nisin adsorption. Zeocarb 216 (Permutit Co. Ltd., London) adsorbed nisin, the maximum adsorption being obtained when the Zeocarb was used in the $\mathrm{H}^{+}$form, but no elution was possible. The Amberlite resins I RC-50; I RA-400 and IR-4B (British Drug Houses Ltd., London) were also tried, of which the first two adsorbed nisin; the resin I RC-50 was mainly used. Columns were prepared according to the makers' suggestions for the removal of basic amino-acids. The column was buffered with acetate buffer at $\mathrm{pH} 4 \cdot 5-5 \cdot 0$, when about $60-70 \%$ of the nisin was adsorbed, with a culture fluid: resin ratio of $20: 1$. Nisin was recovered quantitatively by elution with cold $80 \%$ ethanol containing $0.18 \% \mathrm{HCl}(\mathrm{HCl}$ concentration $0.05 \mathrm{~N}$ ). Although $100 \%$ recoveries of nisin were obtained, the purity of this resin-adsorbed nisin was disappointing. The activity was only 100,000 units/g. which compared unfavourably with the dried chloroform gel (Mattick \& Hirsch, 1947) which had an activity of 500,000-1,000,000 units/ml.

When a growing culture was put over columns of the resin $I$ RC-50 further growth was stopped; uninoculated broth treated in the same way no longer supported growth. Therefore this resin was unspecific and essential nutrients as well as nisin were removed from media.

The effect of frothing was then tried. Nitrogen containing $5 \% \mathrm{CO}_{2}$ was bubbled into a growing culture, the $\mathrm{pH}$ of which was maintained by periodically removing the lactic acid over columns of Deacidite $\mathbf{E}$. A 1 in. diameter glass tube, sloping at about $30^{\circ}$ was inserted into the top of the conical flask and the rate of bubbling so adjusted that the froth travelled about 5-6 ft. along the glass tube before it was collected. By this means a dry froth having a high nisin activity was obtained. As the fermentation proceeded and the foam produced became less stable, the glass tube was gradually shortened to $3 \mathrm{ft}$. In the end an average of about $90 \%$ of the nisin was concentrated into about $\frac{1}{10}$ th the original volume of culture fluid, the growth in the remaining $\frac{9}{10}$ ths of the medium proceeding normally.

The culture fluids thus obtained were free from lactic acid and nisin, but optical densities greater than those obtained by the neutralization technique were not produced. The possibility therefore existed that toxic products other than the above two had also accumulated and were not removed. An experiment to test this point was done. A culture was grown in medium 22 (Table 3) for $4 \mathrm{hr}$., at which time a perceptible turbidity had appeared. This culture 
(pH 6.4) was then centrifuged and the cells resuspended in $\frac{1}{10}$ th volume of the supernatant clear broth. This concentration corresponded with the highest optical density obtained during fermentations. The concentrated cells were re-incubated for $18 \mathrm{hr}$. but no further change of optical density resulted; the $\mathrm{pH}$ during this time decreased to $4 \cdot \mathbf{8}$. This experiment shows that a maximum limiting population density ('M-concentration', Bail, 1929) is reached with this culture. Provided that there was no exhaustion of the medium and no excess of ionized lactic acid, the M-concentration was the same if $(a)$ substances presumably toxic were allowed to accumulate, $(b)$ the two known toxic products were removed, $(c)$ young cells were concentrated into a small volume of their own unspent medium.

\section{DISCUSSION}

Following the observations recorded above a 20-30-fold increase in the yield of nisin has been achieved. In the meat-extract peptone medium used it has been shown that Ca pantothenate becomes exhausted, when the limiting effect of lactic acid is neutralized. It is known that pantothenic acid occurs in coenzyme $\mathbf{A}$ for acetylation and also leads to an increase in pyruvate oxidation (Gunsalus, 1948) and is thus concerned in glycolysis.

There is now little doubt that nisin is a synthetic rather than a breakdown product. Oxford (1945) showed that diplococcin is synthesized by the growing organisms in a medium in which casein hydrolyzed to amino-acids is used. Similar observations were recorded in the course of this work. Low yields of nisin may also be obtained in media containing only amino-acids added individually as such. Moreover, the results in this paper show that the formation of nisin is preceded by considerable metabolic activity and breakdown of glucose. It is possible that the pantothenic acid requirement is connected with this latter process.

It has also been shown that an M-concentration is reached which does not depend on the supply of nutrients or the accumulation of toxic products, a somewhat surprising finding in the case of a vigorous lactic acid-producing organism. This finding rather calls into question the suggestion that the Mconcentration is reached because of exhaustion of the oxygen supply (Topley \& Wilson, 1946). Rahn \& Richardson (1942) found, on the contrary, that vigorous aeration retarded the growth of Strep. lactis. It is a reasonable assumption that the underlying principles for the attainment of an M-concentration are the same in Strep. lactis (as shown in this work) and in Shigella and other organisms (Bail, 1924, 1925).

It appears that no further increases of nisin yields can be expected along the lines of this work, i.e. the production of a maximum number of cells $/ \mathrm{ml}$. of culture. That the alternative specific diversion of some enzyme systems into nisin production is possible is shown by the effect of $\mathrm{Na}_{2} \mathrm{SO}_{4}$ incorporated in the medium. Nisin is known to contain about 5-7\% sulphur (Falconer, 1949).

Little is known about the endo- or exo-cellular nature of nisin. It appears at the moment that an equilibrium between nisin in the cells and nisin in the broth exists, and this depends mainly on $\mathrm{pH}$. 
I wish to thank Dr A. T. R. Mattick for his suggestions and helpful criticism, and Mr L. J. Meanwell, of United Dairies Ltd., for the supply of the parent culture used in this work. My best thanks are due to Miss V. M. Kingsmill for technical assistance. Miss D. M. Wheater, Miss E. Grinsted, Mr F. Wilby and Dr N. J. Berridge have also helped in the course of this work.

\section{REFERENCES}

Ayres, S. H., Rupp, H. \& Johnson Jr., W. T. (1923). The influence of surface tension depressants on the growth of streptococci. J. Bact. 33, 202.

BAIL, O. (1924). Untersuchungen über die M-konzentration von Bakterien und Bakteriophagen. Arch. Hyg., Berl., 94, 54.

BaIL, O. (1925). Gesetze von Bakterien Populationen; Soziologische Studien an Dysenteriebazillen. Arch. Hyg., Berl., 95. 1.

BAIL, O. (1929). Ergebnisse experimentaller Populations forschung. ImmunForsch. $60,1$.

Bernheimer, A. W. \& Pappenheimer Jr., A. M. (1942). Factors necessary for massive growth of Group A haemolytic streptococci. J. Bact. 43, 481.

Berridge, N. J. (1949). Preparation of the antibiotic nisin. Biochem. J. 45, 486.

Bovarnick, M. (1942). The formation of extracellular d(-) glutamic acid polypeptide by B. subtilis. J. biol. Chem., 145, 415.

Falconer, R. (1949). Private communication.

Guirard, B. M., Snell, E. E. \& Williams, R. J. (1946). The nutritional role of acetate for lactic acid bacteria. Arch. Biochem. 9, 361.

Gunsalus, I. C. (1948). Bacterial Metabolism. Ann. Rev. Biochem. 17, 649.

Hirsch, A. (1950). The assay of the antibiotic nisin. J. gen. Microbiol., 4, 70.

Hirsch, A. \& Mattick, A. T. R. (1949). Some recent applications of nisin. Lancet. ii, 190.

Mattick, A. T. R. \& Hirsch, A. (1944)). A powerful inhibitory substance produced by Group N streptococci. Nature, Lond., 154, 551.

Mattick, A. T. R. \& Hirsch, A. (1947). Further observations on an inhibitory substance (nisin) from lactic streptococci. Lancet, ii, 5 .

Niven Jr., C. F. (1944). Nutrition of Strep. lactis. J. Bact., 47, 343.

Oxford, A. E. (1945). Production of the antibacterial protein diplococcin in a medium containing no protein or polypeptide. Biochem. J., 39, xiii.

Rahn, O. \& Rrchardson, G. L. (1942). Oxygen demand and oxygen supply. J. Bact. 44, 321.

Rogers, L. A. (1928). The inhibitory effect of Strep. lactis on Lactobacillus bulgaricus. J. Bact. 16, 321.

Rogers, L. A. \& Whittier, E. O. (1928). Limiting factors in the lactic fermentation. J. Bact. 16, 211.

Taylor, J. I., Hirsch, A. \& Mattick, A. T. R. (1949). The treatment of bovine streptococcal and staphylococcal mastitis with nisin. Vet. Rec., 61, 197.

Topley and Wilson's Principles of Bacteriology and Immunity (1946). 3rd ed. p. 96. Wilson, G. S. \& Miles, A. A. London: Edward Arnold and Co. 